\title{
Platelet aggregation in traumatic spinal cord injury
}

\author{
G Ersoz ${ }^{1}$, H Ficicilar $^{1}$, M Pasin ${ }^{1}$, R Yorgancioglu ${ }^{2}$ and S Yavuzer*,1 \\ ${ }^{1}$ Ankara University Medical School, Department of Physiology, Sihhiye, Ankara 06100, Türkiye; ${ }^{2}$ Health Ministery \\ Ankara Rehabilitation Center, Sihhiye, Ankara 06100, Türkiye
}

\begin{abstract}
Study design: Collagen-induced platelet aggregation and platelet count of ten paraplegic patients (four females, six males, aged 16-42 years) with traumatic spinal cord injury (SCI) (posttraumatic 12-48 weeks) and of ten age-matched healthy volunteers (control group; five females, five males, aged $18-37$ years) were investigated.

Objectives: Investigation of platelet aggregation in the whole blood of the patients with SCI. Setting: Ankara/Turkey.

Methods: Platelet aggregation was evaluated by impedance technique using Chrono Log Model $560 \mathrm{WB}$ aggregometer in whole blood. Platelet count was determined by Medonic Cell Analyser 610.

Results: Maximal intensity of collagen-induced platelet aggregation of the patients was $18.50 \pm 8.28 \mathrm{ohm}($ mean $\pm \mathrm{SD})$ and of the controls was $7.60 \pm 4.25 \mathrm{ohm}$. Maximal rate of collagen-induced aggregation of platelets from the patients was $3.98 \pm 1.59 \mathrm{ohm} / \mathrm{min}$, maximal rate of aggregation of platelets from the controls was $1.57 \pm 1.01 \mathrm{ohm} / \mathrm{min}$. Platelet counts of the patients and controls were $290500 \pm 50357 / \mathrm{mm}^{3}$ and $273000 \pm 48343 / \mathrm{mm}^{3}$ respectively. It was determined that both maximal rate $(P<0.001)$ and maximal intensity $(P<0.01)$ of collagen-induced platelet aggregation of the patients were significantly higher than those of the controls. There was no significant difference between the two groups in respect to platelet counts.

Conclusion: Collagen-induced platelet aggregation of patients with traumatic SCI 12-48 weeks after the trauma was significantly higher than that of the controls. Our results indicate that increased tendency of platelet aggregation, which is probably induced by free radicals, may have a great impact on the late thromboembolic complications reported in patients with traumatic SCI.
\end{abstract}

Keywords: spinal injury; platelet aggregation; oxidative stress

\section{Introduction}

Acute spinal cord injury (SCI) is complicated by venous thrombosis in $70-100 \%$ of cases. ${ }^{1,2}$ It is suggested that immobility, vascular dilatation and endothelial damage promote the development of venous thrombosis in these patients. ${ }^{1,3,4}$ Little is known about platelet function in the posttraumatic acute period of SCI. ${ }^{5,6}$ Although it is considered that risk of venous thrombosis decreases approximately 20 days after the injury, there are sporadic reports about these complications occurring months later. ${ }^{2}$ Winther $e t a l^{3}$ found an increase in euglobulin clot lysis time (ECLT) of patients with cervical spinal cord lesion a minimum of 2 years after trauma. They reported that plasma fibrinogen, activated partial thromboplastin time (a-PTT), thromboplastin time (TT), partial thromboplastin time (PTT), antithrombin III, platelet count, ADP and adrenalininduced platelet aggregation and $\beta$ thromboglobulin $(\beta-$ TG) release in the patients with spinal injury of 2 years

*Correspondence: Sema Yavuzer, Ankara Üniversitesi Tip Fakültesi, Morfoloji Binasi 06100 Ankara-Türkiye duration were not different from that of controls. Kahn et $a l^{7}$ also reported that the aggregation profiles of platelets from the patients with SCI of a minimum 5 years duration were similar to the aggregation profiles of the platelets from the controls.

There has been no information about platelet function within the first year after injury. The aim of this study was to investigate in vitro platelet aggregation in the whole blood of patients with SCI. In order to eliminate the effects of endothelial damage and immobility the study was performed $12-48$ weeks after the trauma.

\section{Materials and methods}

Ten paraplegic patients, four females and six males (mean age 26.6 years with a range of $16-42$ years) with spinal cord injury due to trauma were enrolled in this study. All subjects underwent rehabilitation in the Health Ministry Ankara Rehabilitation Center. Four of the patients were smokers (20 cigarettes/day). No 
alcohol abuse was recorded. None had cardiac problems and their arterial pressures were within normal ranges. One of the patients developed deep venous thrombosis (DVT) two weeks after the study. Detailed demographic variables and injury characteristics are given in Table $1 .^{8}$

An aged-matched group of ten healthy volunteer subjects, five females, five males (mean age 23.3, with a range of $18-37$ years) acted as control. Three of the controls were smokers $(10-15 /$ day $)$. None had a history of alcohol abuse.

Blood samples were taken from fasting patients and controls after resting $15 \mathrm{~min}$ in the supine position between $09.00-11.00 \mathrm{~h}$. None of the patients and the controls had smoked $12 \mathrm{~h}$ prior to the study and had not taken any medication 2 weeks prior to the study. The patients that had to take medication that might affect platelets were excluded.

The samples were drawn into test tubes containing $3.8 \%$ trisodium citrate (in a ratio 1:9) and incubated for $2 \mathrm{~min}$ at $37^{\circ} \mathrm{C}$. Platelet aggregation was evaluated by impedance technique using a Chrono Log Model 560 WB aggregometer in whole blood. ${ }^{9}$ A pair of platin electrodes were placed in $500 \mu \mathrm{l}$ of blood, diluted with $500 \mu \mathrm{l}$ of $0.9 \%$ saline solution. The aggregation pen was moved to the 90 line on the top of the recorder chart. The impedance gain was set so that 20 ohms was 40 small divisions on the chart. The chart was allowed to run $2 \mathrm{~cm} / \mathrm{min}$.

Collagen ( $2 \mu \mathrm{g} / \mathrm{ml}$ final concentration) was added in the samples. The increase in impedance due to adhesion and aggregation of platelets to the electrodes was recorded. Maximal aggregation intensity and maximal aggregation rate were calculated on the aggregation curve. The maximal intensity was determined by maximal deviation of the aggregation pen. The maximal rate, that was determined by drawing tangent, was the slope of the steepest part of the curve (Figure 1). Platelet count was determined by a Medonic Cell Analyser 610.

\section{Statistical analysis}

The results were presented as mean \pm SD. The differences in variables (maximal aggregation intensity, maximal aggregation rate, platelet count) between the patient and control groups were compared using Student's $t$-test. Differences were considered significant when $P<0.05$.

\section{Results}

The individual values of maximal intensity and rate of the patients and the controls are given at Table 2 . Maximal intensity of collagen-induced platelet aggregation of the patients was $18.50 \pm 8.28 \mathrm{ohm}$ and of the controls was $7.60 \pm 4.25 \mathrm{ohm}$ (Figure 2). Maximal rate of collagen-induced aggregation of platelets from the patients was $3.98 \pm 1.59 \mathrm{ohm} / \mathrm{min}$, maximal rate of aggregation of platelets from the controls was $1.57 \pm 1.01 \mathrm{ohm} / \mathrm{min}$ (Figure 2). Both maximal intensity $(t=3.70, P<0.01)$ and maximal rate $(t=4.05$, $P<0.001)$ of platelet aggregation of the patients were

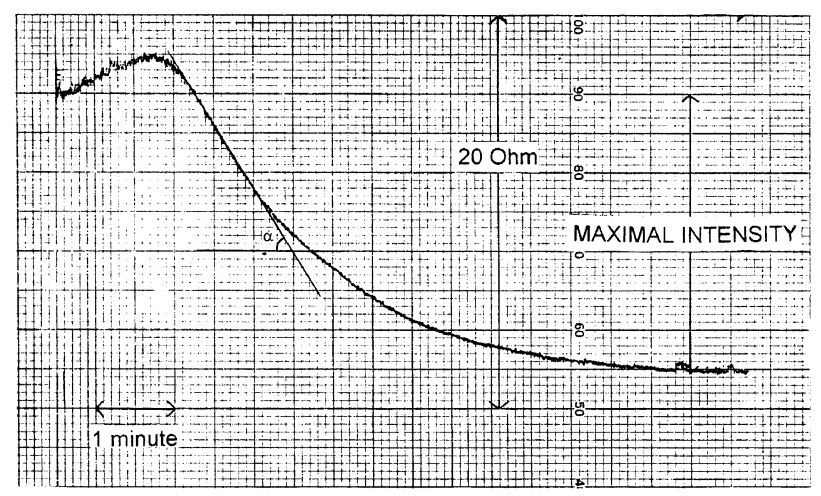

Figure 1 Maximal intensity and maximal rate $(\operatorname{tang} \alpha)$ of aggregation

Table 1 Demographic variables and injury characteristics of the patients with spinal cord injury

\begin{tabular}{|c|c|c|c|c|c|c|c|c|c|c|}
\hline Patient & Age & Sex & $\begin{array}{l}\text { Smoking/ } \\
\text { alcohol }\end{array}$ & $\begin{array}{l}\text { Level of } \\
\text { injury }\end{array}$ & $\begin{array}{l}\text { Level of } \\
\text { function* }^{*}\end{array}$ & $\begin{array}{l}\text { Duration of } \\
\text { injury }\end{array}$ & $\begin{array}{l}\text { Body } \\
\text { brase }\end{array}$ & $\begin{array}{c}\text { Rehabilitation } \\
\text { program }\end{array}$ & Operation & $\begin{array}{c}\text { Functional } \\
\text { status }^{* *}\end{array}$ \\
\hline 1 & 18 & M & $-1-$ & Th10 & B & 20 weeks & - & exercise & stabilization & WC \\
\hline 2 & 25 & M & $-1-$ & Th6 & A & 18 weeks & - & exercise & stabilization & WC \\
\hline 3 & 35 & M & $+1-$ & L1 & B & 20 weeks & - & exercise & laminectomy & KAFOs \\
\hline 4 & 24 & $\mathrm{~F}$ & $-1-$ & Th10 & A & 44 weeks & + & exercise & stabilization & WC \\
\hline 5 & 42 & $\mathrm{~F}$ & $-1-$ & Th3-5 & A & 16 weeks & - & exercise & laminectomy & WC \\
\hline 6 & 25 & M & $+1-$ & Th11-12 & B & 16 weeks & + & exercise + paraphin & stabilization & KAFOs \\
\hline 7 & 32 & M & $+1-$ & Th11 & A & 12 weeks & - & exercise & laminectomy + stabilization & WC \\
\hline 8 & 18 & $\mathrm{~F}$ & $-1-$ & Th9 & A & 22 weeks & + & exercise & laminectomy + stabilization & WC \\
\hline 9 & 16 & $\mathrm{~F}$ & $-1-$ & Th12 & $\mathrm{C}$ & 34 weeks & + & exercise & laminectomy & AFOs \\
\hline 10 & 30 & M & $+1-$ & Th9 & B & 48 weeks & + & exercise & laminectomy & WC \\
\hline
\end{tabular}

*Motor Functions were classified according to the Frankel Scale. ${ }^{8} * *$ Functional status of the patients at the end of the rehabilitation programs. Abbreviation: male (M), female (F), thoracal (Th), lumbal (L), wheelchair (WC), knee-ankle-foot orthoses (KAFOs), ankle-foot orthoses (AFOs) 
Table 2 Maximal intensities (Max. Agg. Intensity) and rates (Max. Agg. Rate) of collagen-induced platelet aggregation of the controls and the patients

\begin{tabular}{|c|c|c|c|c|c|c|c|}
\hline & $\begin{array}{c}\text { Max.Agg. Intensity } \\
(\mathrm{ohm})\end{array}$ & $\begin{array}{l}\text { Controls } \\
\text { Max.Agg. Rate } \\
\quad \text { (ohm } / \mathrm{min})\end{array}$ & $\begin{array}{l}\text { Platelet count } \\
\quad\left(/ \mathrm{mm}^{3}\right)\end{array}$ & & $\begin{array}{c}\text { Max.Agg. Intensity } \\
(\mathrm{ohm})\end{array}$ & $\begin{array}{l}\text { Patients } \\
\text { Max.Agg. Rate } \\
\quad \text { (ohm/min) }\end{array}$ & $\begin{array}{l}\text { Platelet count } \\
\quad\left(/ \mathrm{mm}^{3}\right)\end{array}$ \\
\hline 1 & 6.5 & 1.45 & 240000 & 1 & 28.5 & 5 & 240000 \\
\hline 2 & 3.5 & 1.30 & 216000 & 2 & 23.5 & 4.4 & 230000 \\
\hline 3 & 3 & 0.45 & 286000 & 3 & 24 & 5.5 & 300000 \\
\hline 4 & 2.5 & 0.30 & 230000 & 4 & 28 & 1.2 & 370000 \\
\hline 5 & 15 & 2.95 & 332000 & 5 & 20 & 4.5 & 315000 \\
\hline 6 & 11.5 & 3.35 & 298000 & 6 & 12.5 & 3.5 & 310000 \\
\hline 7 & 7.5 & 1.45 & 210000 & 7 & 10 & 3 & 350000 \\
\hline 8 & 10 & 1.10 & 320000 & 8 & 5.5 & 2.2 & 250000 \\
\hline 9 & 5 & 1.00 & 338000 & $9 *$ & 23 & 6.6 & 230000 \\
\hline 10 & 11.5 & 2.30 & 260000 & 10 & 10 & 3.9 & 310000 \\
\hline
\end{tabular}

*The patient developed DVT 2 weeks after the study
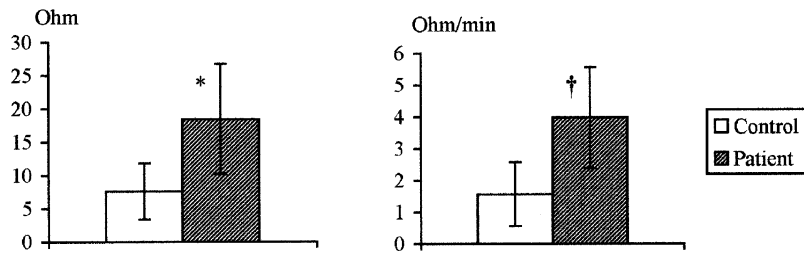

Figure 2 Maximal intensity (ohm) and maximal rate (ohm/ min) of collagen-induced platelet aggregation of the control and the patient groups. ${ }^{*} P<0.01 ; \dagger P<0.001$

higher than those of the controls. The platelet count of the patients was $290500 \pm 50357 / \mathrm{mm}^{3}$, and the platelet count of the controls was $273000 \pm 48343 / \mathrm{mm}^{3}$. There was no significant difference between the platelet counts of two groups $(t=0.79, P>0.05)$.

\section{Discussion}

Since deep venous thrombosis and pulmonary embolism are serious complications, hemostatic changes in the cases of SCI are of considerable clinical interest. Acute thromboembolic complications are thought to be in relation to endothelial damage. ${ }^{1,3}$ Increased factor VIII levels and increased fibrinogen levels have been reported in the posttraumatic acute period. ${ }^{1,4}$ Goodman et $a l^{5}$ reported platelet adhesion and aggregation on to the damaged endothelium $1.25 \mathrm{~min}$ following injury. Fujii et $a l^{6}$ found increased fibrinopeptide A, thrombin/antithrombin III complex and plasma Ddimer levels in patients with thrombosis within $48 \mathrm{~h}$ after trauma. It was suggested that high thrombin/ antithrombin III complex levels have a possible predictive value for thrombosis. They also reported no difference in platelet count, mean platelet volume, platelet factor $4, \beta$ thromboglobulin levels, vWF levels, fibrinogen levels between the groups with and without thrombosis. On the other hand, no significant difference was found between the aggregation response of platelets from patients with SCI in the chronic period (mininum 2 years following the trauma) and from controls. ${ }^{3,7}$

The results of the present study demonstrated that collagen-induced platelet aggregation of the patients was significantly higher than of the controls $12-48$ weeks after the trauma. The differences in the results may be due to the duration of the injury or may be due to the different methods that were used for the evaluation of the platelet aggregation. It was suggested that the measuring platelet aggregation in whole blood by the impedance method was more sensitive than the measuring in platelet rich plasma using an optical method. ${ }^{10}$

Besides physical damage, traumatic spinal injury results in several biochemical, metabolic and inflammatory processes called secondary pathological alterations. ${ }^{11}$ The products of membrane breakdown (including polyunsaturated fatty acids, prostanoids, leukotriens and free radicals), several cations, amino acids, monoamines, neuropeptides are proposed as injury factors. ${ }^{12,13}$

Increased generation of free oxygen species and lipid peroxidation are early biochemical changes in central nervous system trauma. ${ }^{13,14}$ It is suggested that chronic hypoventilation, activation of arachidonic acid metabolism, oxidation of extravasated hemoglobin, infiltration and activation of macrophages and neutrophils are involved in the generation of free radicals. Free radicals cause membrane lipid peroxidation, protein denaturation, DNA damage, inhibition of $\mathrm{Na}^{+}-\mathrm{K}^{+}$ATPase and $\mathrm{Ca}^{2+}$ ATPase. ${ }^{12-15}$

Platelets are known to be sensitive to oxidative stress. It was reported that $\mathrm{H}_{2} \mathrm{O}_{2}$ and a superoxide radical increased the rate of ADP and collageninduced platelet aggregation. ${ }^{16,17}$ Free radicals modify membrane organization and $\mathrm{Ca}^{2+}$ homeostasis of platelets. Lipid peroxidation results in formation of $\mathrm{TxA}_{2}$, hydrolysis of diacylglycerol and inhibition of 
membrane-bounded enzymes. ${ }^{16,18}$ On the other hand, free radicals inhibit $\mathrm{PGI}_{2}$ synthetase and $\mathrm{TxA}_{2} / \mathrm{PGI}_{2}$ imbalance occurs. ${ }^{16}$ In our previous study, we found lower superoxide dismutase (SOD) and catalase (CAT) enzyme activities in the patients with spinal injury within the first year. ${ }^{19}$ It is known that antioxidants play an essential role in the regulation of platelet functions. ${ }^{20}$ SOD and CAT inhibit platelet activation. ${ }^{21,22}$ It is thought that insufficient antioxidant capacity in SCI results in insufficient detoxification of free radicals and causes oxidative stress and may increase platelet activity.

In conclusion our results suggested that platelet activation may have a great impact on the thromboembolism phenomenon which has been previously reported in patients with spinal cord injury. Oxidative stress may play an essential role in platelet activation. It seems that it is important to continue antithrombotic therapy at least within the first year in the patients who have increased platelet aggregation rates.

\section{References}

1 Petaja J, Myllynen P, Rokkanen P, Nokelainen M. Fibrinolysis and spinal injury. Relationship to post-traumatic deep vein thrombosis. Acta Chir Scand 1989; 155: $241-246$.

2 Green D et al. Prevention of thromboembolism after spinal cord injury using low-molecular-weight heparin. Ann Intern Med 1990; 113: $571-574$.

3 Winther K, Gleerup G, Snorrason K, Biering-Sorensen F. Platelet function and fibrinolytic activity in cervical spinal cord injured patients. Thromb Res 1992; 65: 469-474.

4 Karaca M, Nilsson IM. Fibrinolytic activity in hemiplegic patients. Acta Med Scand 1971; 189: 325-329.

5 Goodman JH, Bingham Jr WG, Hunt WE. Platelet aggregation in experimental spinal cord injury. Ultrastructural observations. Arch Neurol 1979; 36: 197-201.

6 Fujii Y et al. Thrombosis in spinal cord injury. Thromb Res 1992; 68: $357-368$.

7 Kahn NN, Bauman WA, Sinha AK. Loss of high affinity prostacyclin receptors in platelets and the lack of prostaglandin-induced inhibition of platelet-stimulated thrombin generation in subjects with spinal cord injury. Proc Natl Acad Sci 1996; 93: $245-249$.
8 Wade DT. Spinal injury Frankel Scale. In: Measurement in neurological Rehabilitation. Oxford University Press: 1992, pp 354.

9 Cardinal DC, Flower RJ. The electronic aggregometer: a novel device for assessing platelet behavior in blood. $J$ Pharmacol Methods 1980; 3(2): 135-158.

10 Hendra TJ et al. Exercise-induced changes in platelet aggregation; a comparison of whole blood and platelet rich plasma techniques. Thromb Res 1988; 52: 443-451.

11 Hsu CY, Halushka PV, Hogan EL, Cox RD. Increased thromboxane level in experimental spinal cord injury. $J$ Neurol Sci 1986; 74: 289-296.

12 Saunders RD et al. Effects of methylprednisolone and the combination of alpha-tocopherol and selenium on arachidonic acid metabolism and lipid peroxidation in traumatized spinal cord tissue. J Neurochem 1987; 49: 24-31.

13 Faden AI. Experimental neurobiology of central nervous system trauma. Crit Rev Neurobiol 1993; 7: 175-186.

14 Hall ED, Braughler JM. Free radicals in CNS injury. In: Waxman SG (ed). Molecular and Cellular Approaches to the Treatment of Neurological Disease. Raven Press Ltd: New York 1993, pp 81-105.

15 Janssen L, Hansebout RR. Pathogenesis of spinal cord injury and newer treatments. A review. Spine 1989; 14: 23-32.

16 Salvemini D, de Nucci G, Sneddon JM, Vane JR. Superoxide anions enhance platelet adhesion and aggregation. $\mathrm{Br} J$ Pharmacol 1989; 97: 1145-1150.

17 Del Principe $\mathrm{D}$ et al. Hydrogen peroxide has a role in the aggregation of human platelets. FEBS Lett 1985; 185: $142-146$.

18 Ohyashiki T, Kobayashi M, Matsui K. Oxygen-radical-mediated lipid peroxidation and inhibition of ADP-induced platelet aggregation. Arch Biochem Biophys 1991; 288: 282-286.

19 Ficicilar $\mathrm{H}$ et al. Intracellular antioxidant enzyme activities in patients with traumatic spinal cord injury. Ankara Üniversites Tip Fakültesi Mecmuasi 1996; 49: 191-195. Turkish. English abstract available.

20 Salonen JT. Antioxidants and platelets. Ann Med 1989; 21: 59 62

21 Violi F et al. Influence of hydroxyl radical scavengers on platelet function. Haemostasis 1988; 18: 91 -98.

22 Buczynski A et al. Changes in antioxidant enzymes activities, aggregability and malonyldialdehyde concentration in blood platelets from patients with coronary heart disease. Atherosclerosis 1993; 100: $223-228$. 